\title{
¿Satellite Observations of Regional Drought Severity in the Continental United States Using GRACE-Based Terrestrial Water Storage Changes ${ }^{\mathscr{D}}$
}

\author{
Meng Zhao AND Geruo A \\ Department of Earth System Science, University of California, Irvine, Irvine, California \\ ISABELLA VELICOGNA \\ Department of Earth System Science, University of California, Irvine, Irvine, and Jet Propulsion Laboratory, \\ California Institute of Technology, Pasadena, California \\ JOHN S. KIMBALL \\ Numerical Terradynamic Simulation Group, College of Forestry and Conservation, University of Montana, \\ Missoula, Montana
}

(Manuscript received 17 June 2016, in final form 8 May 2017)

\begin{abstract}
Drought monitoring is important for characterizing the timing, extent, and severity of drought for effective mitigation and water management. Presented here is a novel satellite-based drought severity index (DSI) for regional monitoring derived using time-variable terrestrial water storage changes from the Gravity Recovery and Climate Experiment (GRACE). The GRACE-DSI enables drought feature comparison across regions and periods, it is unaffected by uncertainties associated with soil water balance models and meteorological forcing data, and it incorporates water storage changes from human impacts including groundwater withdrawals that modify land surface processes and impact water management. Here, the underlying algorithm is described, and the GRACEDSI performance in the continental United States during 2002-14 is evaluated. It is found that the GRACE-DSI captures documented regional drought events and shows favorable spatial and temporal agreement with the monthly Palmer Drought Severity Index (PDSI) and the U.S. Drought Monitor (USDM). The GRACE-DSI also correlates well with a satellite-based normalized difference vegetation index (NDVI), indicating sensitivity to plantavailable water supply changes affecting vegetation growth. Because the GRACE-DSI captures changes in total terrestrial water storage, it complements more traditional drought monitoring tools such as the PDSI by providing information about deeper water storage changes that affect soil moisture recharge and drought recovery. The GRACE-DSI shows potential for globally consistent and effective drought monitoring, particularly where sparse ground observations (especially precipitation) limit the use of traditional drought monitoring methods.
\end{abstract}

\section{Introduction}

Drought indices are convenient ways to characterize drought because they compress the complexity of the drought phenomenon into a single number. Commonly

D Denotes content that is immediately available upon publication as open access.

Supplemental information related to this paper is available at the Journals Online website: http://dx.doi.org/10.1175/ JCLI-D-16-0458.s1.

Corresponding author: Meng Zhao, mzhao4@uci.edu used indices are generally sensitive to only a few hydrological components and cannot provide a complete representation of the water deficit during drought. For instance, the Palmer Drought Severity Index (PDSI) is sensitive to atmospheric moisture demand and nearsurface soil moisture content, and has been frequently used as a measure of meteorological and soil moisture drought (Mishra and Singh 2010; Trenberth et al. 2014). Observing all relevant hydrological variables (i.e., snow, surface water, soil moisture, and groundwater) is important for fully characterizing drought propagation and recovery, and associated ecosystem impacts (Van Loon 2015). Previous studies have used Gravity Recovery and Climate Experiment (GRACE)-derived terrestrial water storage (TWS) estimates to examine regional-scale 
droughts (Yirdaw et al. 2008; Chen et al. 2009; Leblanc et al. 2009; Long et al. 2013; Castle et al. 2014; Cao et al. 2015) and to quantify drought-induced water storage deficits (Thomas et al. 2014). The drought index for Texas in McCandless (2014) combines TWS, precipitation, and the satellite-based normalized vegetation difference index (NDVI) and it is sensitive to vegetation drought response over semiarid areas. These methods are not suitable for comparing drought features for different locations and time periods as they do not account for the spatiotemporal variability of local hydroclimate. For example, the same amount of water deficit may have a larger impact on arid and humid biomes than on semiarid and semihumid biomes (Vicente-Serrano et al. 2013). The same amount of water deficit may also induce more severe damage to vegetation during reproductive growth stages than during green-up and senescence ( $\mathrm{Ji}$ and Peters 2003). Houborg et al. (2012) accounted for these differences by deriving region-specific cumulative distribution of dry and wet conditions from GRACE data assimilation system, but this approach may not be readily useable outside North America.

To overcome these limitations, we develop a new standardized drought severity index (DSI) based solely on GRACE TWS estimates, herein referred to as GRACE-DSI. Here, we introduce the GRACE-DSI algorithm, evaluate how it captures the space and time evolution of documented regional drought events during 2002-14, compare it with the PDSI and the U.S. Drought Monitor (USDM), and demonstrate its synergistic use with traditional drought monitoring tools across the continental United States (CONUS). The CONUS domain was selected owing to a dense surface station network, reliable PDSI, and diverse climate and vegetation conditions. We also compare the GRACEDSI against the NDVI from the Moderate Resolution Imaging Spectroradiometer (MODIS) used as a proxy for vegetation growth changes. Finally, we discuss the merits of combining the GRACE-DSI with other datasets for drought characterization and potential applications for monitoring water supply and ecosystem interactions in other areas.

\section{Data and methodology}

a. Data

We use release-05 GRACE gravity solutions in the form of spherical harmonic coefficients truncated to degree 60, from the Center for Space Research at the University of Texas, for the period April 2002-October 2014. The GRACE-derived $\mathrm{C}_{20}$ coefficients are replaced with satellite laser ranging estimates (Cheng et al. 2013). We include degree- 1 coefficients calculated as in Swenson et al. (2008). We correct the glacial isostatic adjustment signal using A et al. (2013). To reduce correlated errors, we filter each monthly field following Swenson and Wahr (2006). We smooth the Stokes coefficients using a 350-km radius Gaussian averaging function (Wahr et al. 1998) and calculate regular $1^{\circ} \times 1^{\circ}$ latitude-longitude monthly TWS mass anomalies relative to the 2002-14 mean.

We use the monthly self-calibrated PDSI from Dai (2011) on a global $2.5^{\circ}$ grid. The PDSI uses a two-layer bucket model to assess soil water balance by accounting for water supply and demand (Palmer 1965). Dai et al. (2004) found good correlations of PDSI with soil moisture observations over the United States, the former Soviet Union, Mongolia, and China, and with streamflow over major global river basins.

We use remotely sensed monthly soil moisture (SM) data from the European Space Agency Climate Change Initiative (Liu et al. 2011, 2012). The SM record employs passive and active microwave satellite data with improved spatial and temporal coverage and resolution.

We use the cloud-free MODIS monthly Climate Model Grid $0.05^{\circ}$ NDVI product (MOD13C2; Huete et al. 2002) as a measure of vegetation activity. We only use data from the growing season (April-October) to avoid snow-related NDVI noise (Ji and Peters 2003; Karnieli et al. 2010; Mu et al. 2013; A et al. 2015).

We use the USDM weekly shapefiles distributed by the National Drought Mitigation Center (http:// droughtmonitor.unl.edu). The USDM integrates information from many existing drought indicators, including the PDSI, along with local reports from state climatologists and observers across the country. The shapefiles are converted to monthly raster composites in a $1^{\circ}$ grid. For computational purposes, the USDM drought classes are mapped to numerical values with "no drought" assigned a value of $0, \mathrm{D} 0=1$ (abnormally dry), D1 = 2 (moderate drought), D2 = 3 (severe drought), D3 $=4$ (extreme drought), and D4 $=5$ (exceptional drought).

\section{b. GRACE-DSI}

For each $1^{\circ}$ grid cell, we calculate the GRACE-DSI as the standardized anomalies of GRACE TWS for month $j$ and year $i$, as GRACE-DSI ${ }_{i, j}=\left(\mathrm{TWS}_{i, j}-\right.$ $\left.\left\langle\mathrm{TWS}_{j}\right\rangle\right) / \sigma_{j}$, with $i$ ranging from 2002 to 2014, where $\left\langle\mathrm{TWS}_{j}\right\rangle$ and $\sigma_{j}$ are the mean and standard deviation of TWS anomaly for month $j$, respectively. The global GRACE-DSI follows a pseudo-standard normal distribution. We classify the GRACE-DSI into five drought categories (Table 1) by matching their ranking percentiles to thresholds used by the USDM (i.e., $30 \%$, $20 \%, 10 \%, 5 \%$, and $2 \%$ ) (Svoboda et al. 2002). For example, the cumulative relative frequency for GRACE-DSI 
TABLE 1. Dynamic range and relative categories for wet $(\mathrm{W})$ and dry (D) conditions of GRACE-DSI and PDSI-Z. The drought classification scheme is consistent with the USDM.

\begin{tabular}{clc}
\hline \hline Category & \multicolumn{1}{c}{ Description } & GRACE-DSI and PDSI-Z \\
\hline W4 & Exceptionally wet & 2.0 or greater \\
W3 & Extremely wet & 1.60 to 1.99 \\
W2 & Very wet & 1.30 to 1.59 \\
W1 & Moderately wet & 0.80 to 1.29 \\
W0 & Slightly wet & 0.50 to 0.79 \\
WD & Near normal & 0.49 to -0.49 \\
D0 & Abnormally dry & -0.50 to -0.79 \\
D1 & Moderate drought & -0.80 to -1.29 \\
D2 & Severe drought & -1.30 to -1.59 \\
D3 & Extreme drought & -1.60 to -1.99 \\
D4 & Exceptional drought & -2.0 or less \\
\hline
\end{tabular}

less than -2.0 is $2 \%$; therefore, we set -2.0 as the upper cutoff value for exceptional drought. The GRACEDSI detects both drought and abnormally wet events (Table 1).

\section{c. GRACE-DSI evaluation}

Because of the truncation and smoothing applied to reduce short scale errors, each GRACE-DSI grid cell represents conditions averaged over a $350-\mathrm{km}$ radius footprint. For consistency, all datasets are processed as the GRACE data - that is, converted in spherical harmonic, truncated to degree 60 , filtered, smoothed using a $350-\mathrm{km}$ Gaussian averaging function, and converted in the spatial domain on a $1^{\circ} \times 1^{\circ}$ lat/lon grid. This process preserves the time and spatial variability of the original signal but reduces its amplitude (Velicogna and Wahr 2006). To minimize the impact of these changes on the data comparisons, we standardize PDSI and SM data relative to the GRACE-DSI period (2002-14), herein referred to as PDSI-Z and SM-Z, and we employ the same drought classification scheme as for the GRACE-DSI (see Text S1 in the online supplemental material).

We compare the spatial patterns of GRACE-DSI, PDSI-Z, and USDM during the record-setting 2011-12 drought (Hoerling et al. 2014). We examine the temporal correspondence between the GRACE-DSI and PDSI-Z over the CONUS using correlation analysis. The USDM is a discrete metric and does not characterize wetter-thanaverage conditions, preventing a rigorous comparison with GRACE-DSI through correlation analysis. Instead, we map continuous GRACE-DSI to categorical series following the classification scheme in Table 1 and convert the positive side of GRACE-DSI to the no-drought category. At each grid cell, we calculate the ratio of the number of months for which both GRACE-DSI and USDM have the same drought category, relative to the total number of months. We rescale GRACE-like processed USDM using the method described in Landerer and Swenson (2012) and round the rescaled value up to the nearest drought category.

We calculate the correlation coefficients between GRACE-DSI and NDVI for each growing season month separately, as the vegetation drought response varies considerably within different phenological stages and thus cannot be adequately represented by simple correlation or time series comparison without accounting for the seasonal effect ( $\mathrm{Ji}$ and Peters 2003, Karnieli et al. 2010, A et al. 2015, Forkel et al. 2015).

In the GRACE-DSI algorithm, we normalize the TWS deficit by the regional hydroclimatological variability to account for the fact that a TWS deficit of a given magnitude may indicate different drought levels in an arid or humid region. To illustrate this, we show that the same USDM-classified drought severity level corresponds to different TWS deficits depending on the regional hydroclimatology. We focus on the 2011-12 drought and at each grid cell we define for each month the corresponding drought category using the USDM drought classification (D1-D4 drought categories). We then categorize the months into four groups each corresponding to one of the drought classifications. For each group, we identify the month when the maximum TWS deficit occurred, and we calculate the corresponding TWS standard deviations using the entire analyzed period, 2002-14. We investigate the spatial patterns of the maximum TWS deficit in relation to the monthly TWS standard deviation and the regional precipitation climatology.

\section{Results}

The GRACE-DSI captures documented regional drought events during the past decade in the CONUS (see Text S2 and Fig. S1 in the online supplemental material). We also find a remarkable agreement in spatial pattern between the GRACE-DSI, PDSI-Z, and USDM over different seasons and across a wide range of land covers, despite the fact that vegetation, snow, and other cold season land surface processes are not explicitly treated in the PDSI model (Dai 2013; van der Schrier et al. 2013). In 2011, GRACE-DSI and PDSI-Z capture similar drought and wet spatial extent across the CONUS especially from February to August (Fig. 1). The USDM does not provide wetter-than-average information and thus does not reflect the wetting pattern in 2011. When dry weather conditions expand northward after August (NOAA 2012), the PDSI-Z and USDM detect dryness in the western Great Lakes, upper Mississippi Valley, parts of the northern plains, and the far West, whereas the GRACE-DSI indicates 


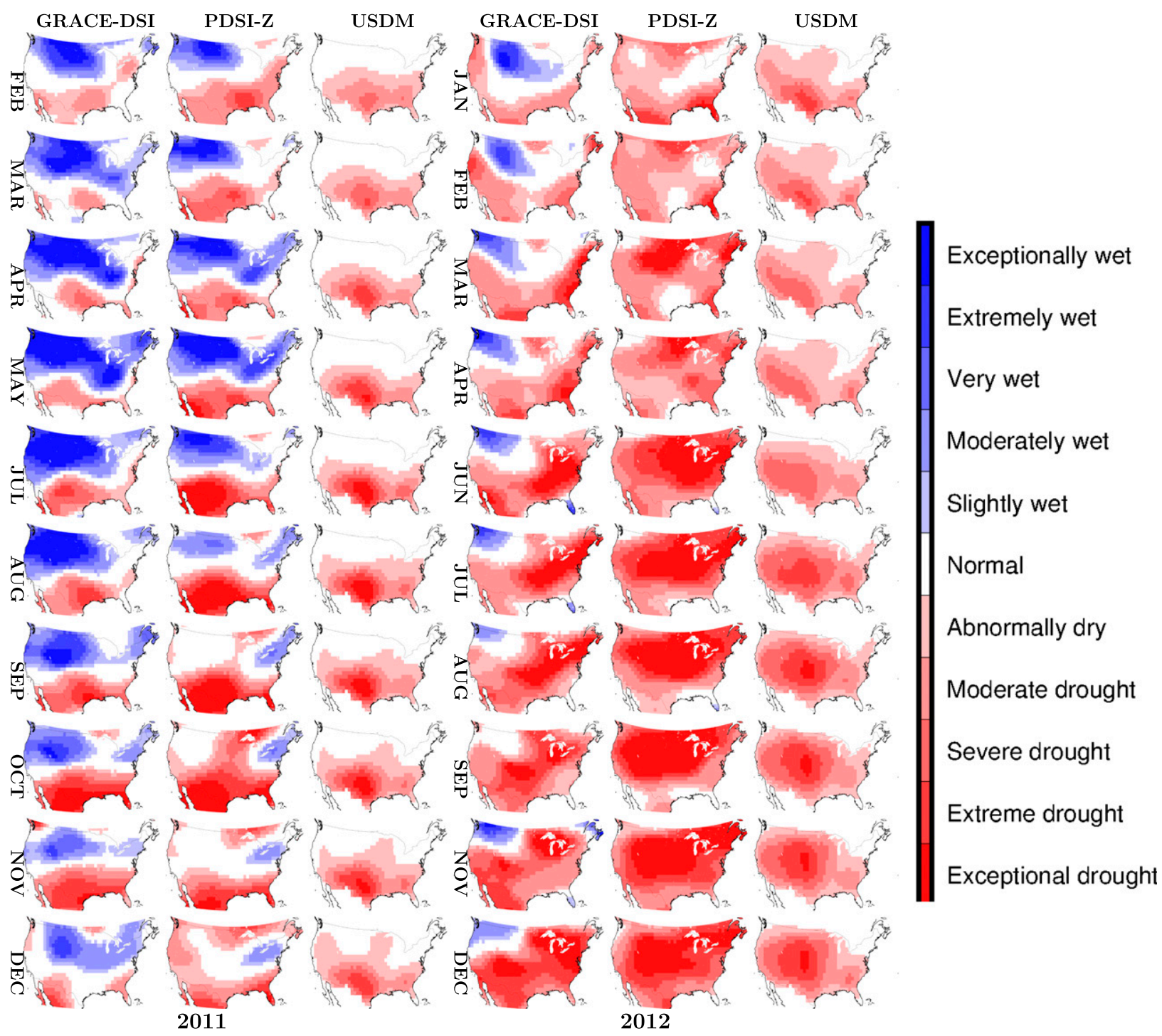

FIG. 1. Spatial comparison of monthly GRACE-DSI, PDSI-Z, and USDM during 2011-12. Months with missing GRACE data are skipped. Color bar shows the drought/wetting categories defined in Table 1. PDSI-Z and GRACE-DSI use the same classification scheme. The drought classification scheme is consistent with the USDM. Note that USDM does not provide wetter-than-average information.

above- or near-normal underlying TWS in these regions. In 2012, a strong heat wave hit the CONUS (Wang et al. 2014). The PDSI-Z and USDM indicate severe drought conditions for all of 2012. In contrast, the GRACE-DSI shows a persistent water storage surplus throughout the year in the Northwest.

We compare GRACE-DSI and PDSI-Z monthly time series at six drought locations representing different land cover and climate zones (Fig. 2). While we find overall favorable correspondence between GRACE-DSI and PDSI-Z across the CONUS, the two indices also provide complementary information regarding surface and total water supply conditions. In California (location 4), both indices capture the water deficit during 2007-09 and the exceptional drought starting in 2012 (Fig. 2e). In late 2014, the PDSI returns to normal values after a short-term rainfall increase (NOAA 2015), while the GRACE-DSI is still indicative of exceptional drought conditions, in agreement with the ongoing groundwater crisis and the extraordinary cumulative precipitation deficit (Famiglietti 2014; Savtchenko et al. 2015).

The monthly GRACE-DSI and PDSI-Z correlation is significant $(p<0.01)$ over the entire CONUS (Fig. 3a). The correlation is strongest in the South and Southeast and has relatively smaller magnitude over the northwestern plains, consistent with the spatial and temporal comparisons in Figs. 1 and 2. To investigate the relatively lower correlation in the northwestern Plains, we compare 
a
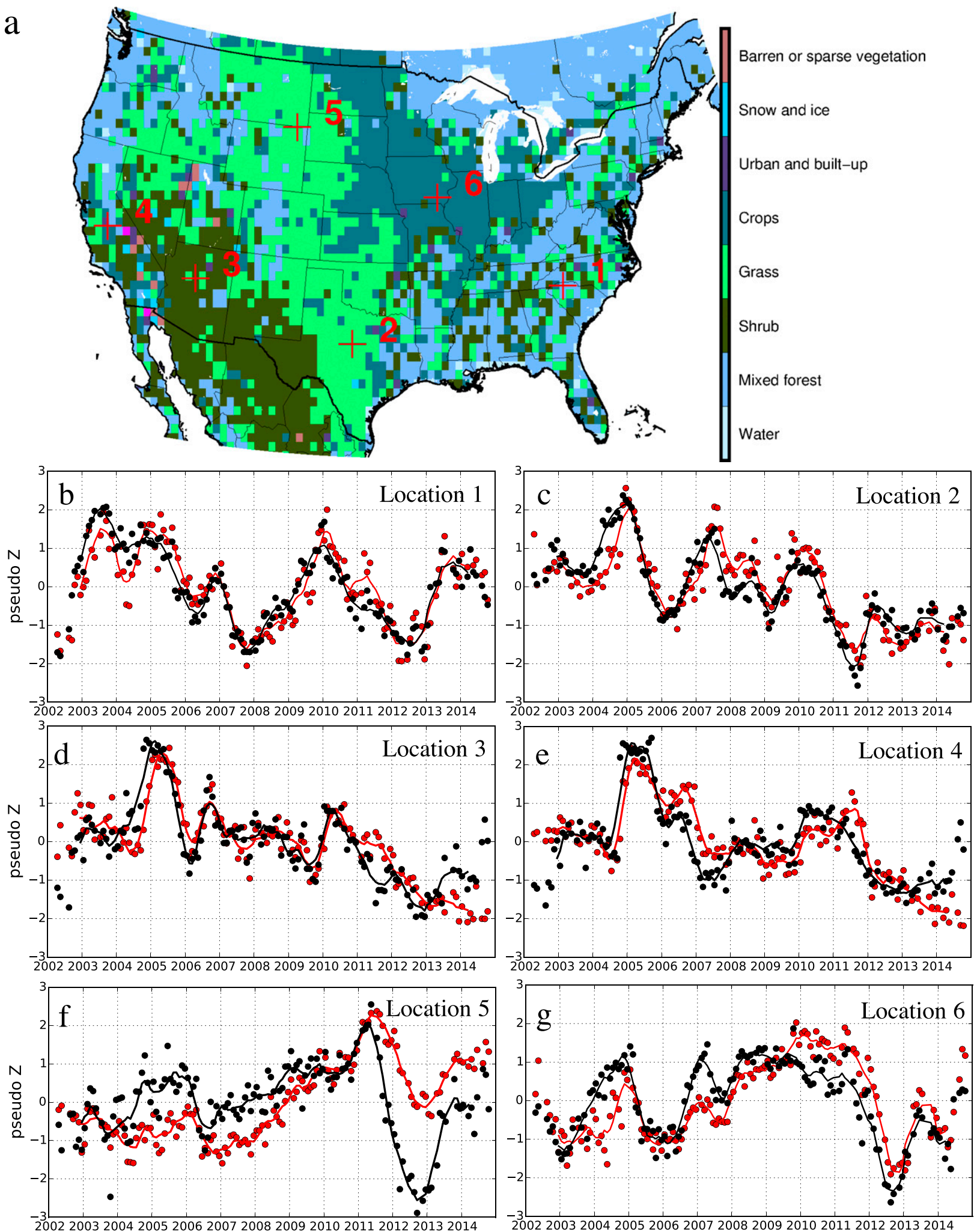

FIG. 2. (a) Land cover map of the CONUS from MODIS land cover type (MCD12Q1) (Friedl et al. 2010). (b)-(g) Time series of GRACE-DSI (red) and PDSI-Z (black) at six locations shown in (a), respectively: $\left(35^{\circ} \mathrm{N}, 82^{\circ} \mathrm{W}\right) ;\left(32^{\circ} \mathrm{N}, 99^{\circ} \mathrm{W}\right) ;\left(35^{\circ} \mathrm{N}, 112^{\circ} \mathrm{W}\right) ;\left(37^{\circ} \mathrm{N}\right.$, $\left.120^{\circ} \mathrm{W}\right) ;\left(45^{\circ} \mathrm{N}, 105^{\circ} \mathrm{W}\right)$; and $\left(41^{\circ} \mathrm{N}, 92^{\circ} \mathrm{W}\right)$. In (b) $-(\mathrm{g})$, dots are index values and lines are smoothed values using a quadratic polynomial filter with a 13 -month window. 


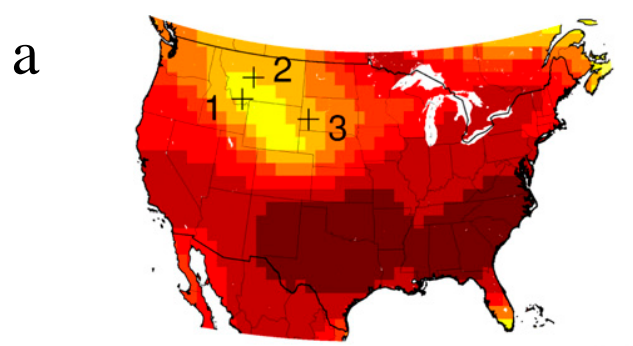

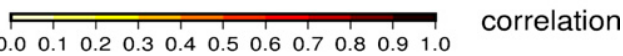

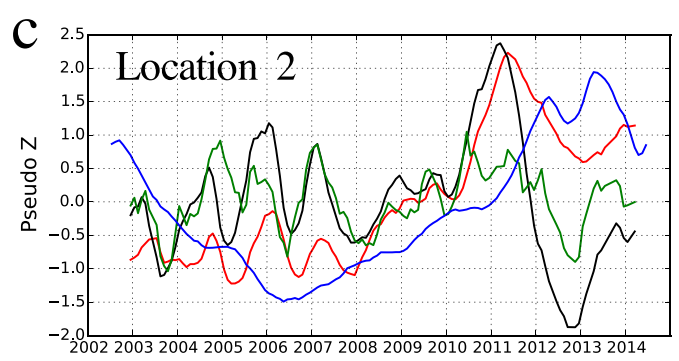

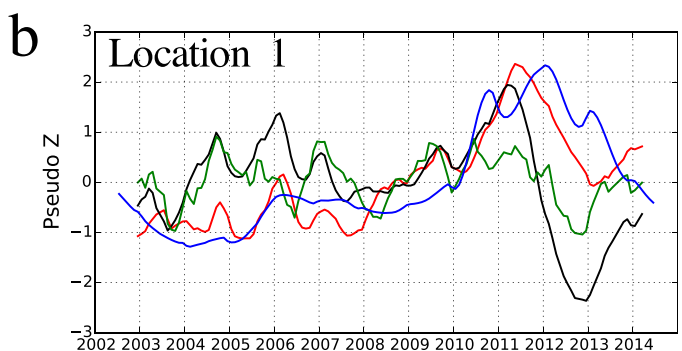

d

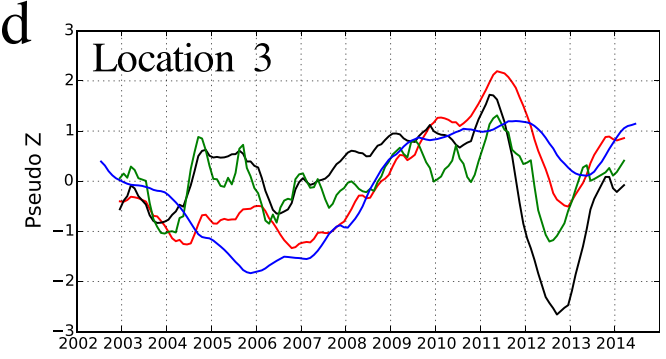

FIG. 3. (a) Temporal cross-correlation coefficient between monthly GRACE-DSI and PDSI-Z during study period. (b)-(d) Times series of GRACE-DSI (red), PDSI-Z (black), satellite-retrieved SM-Z (green), and standardized groundwater depths (blue) for locations 1 to 3 in (a). Geographic coordinates for locations 1, 2, and 3 are $\left(45.09^{\circ} \mathrm{N}, 112.64^{\circ} \mathrm{W}\right),\left(47.37^{\circ} \mathrm{N}, 111.19^{\circ} \mathrm{W}\right)$, and $\left(44.30^{\circ} \mathrm{N}, 103.44^{\circ} \mathrm{W}\right)$, respectively. All lines are smoothed values using a quadratic polynomial filter with a 13-month window.

both indices with the satellite SM record and water table measurements from three wells in the USGS groundwater climate response network (http://groundwaterwatch. usgs.gov) (Fig. 3a). These locations are not impacted by pumping or injection, have 10 years of measurements, and the well records are good representatives of regional groundwater variability in the Missouri watershed (Reager et al. 2015). The GRACE-DSI and PDSI-Z show overall consistent temporal variations, but with a time lag and a shift in magnitude (Figs. 3b-d). In 2004-08, following the 2000-04 drought (Schwalm et al. 2012), the PDSI-Z indicates an overall wetting with episodic dryness consistent with the SM variations, whereas the GRACEDSI indicates drier-than-normal conditions in alignment with observed negative anomalies in groundwater level during this time period despite the difference in spatial scale of GRACE-DSI and well measurements. This is in agreement with a previous study (Anderson et al. 2013) of the northwestern Plains Snake River subarea, where long-term hydrological drought persisted during 2004-08 as shown by the USDM despite increasing surface SM and decreasing evapotranspiration deficit from temporary surface wetting.

Following the warming trend in early 2012 (Wang et al. 2014), the PDSI-Z decreases and reaches exceptional drought in the summer while SM declines later and remains above normal until spring (Figs. 3b-d). The GRACE-DSI decreases later than the PDSI-Z and by a smaller amount, which is consistent with the near-normal to positive groundwater levels throughout 2012.

We evaluate the agreement between GRACE-DSI, PDSI, and USDM in terms of drought severity classification. We calculate the percentage of the number of months for which the USDM and GRACE-DSI (Fig. 4a), USDM and PDSI-Z (Fig. 4d), and USDM and PDSI (Fig. 4g) display the same drought category. We repeat the same calculation with the USDM index biased by one (Figs. 4b,e,h) and two drought categories (Figs. 4c,f,i) to determine the percentage of the total number of months for which GRACE-DSI, PDSI-Z, and PDSI underestimate the USDM drought classification by one or two categories respectively (note that the original no-drought observations remain the same). We find that the GRACE-DSI, PDSI-Z, and original PDSI all tend to underestimate USDM-classified drought by one to two categories in the western United States (Fig. 4).

The GRACE-DSI and NDVI correlation (Fig. 5) is stronger and more widespread during June-September than at the beginning (April-May) or the end (October) of the growing season. At lower latitudes, the correlation becomes significant earlier and extends later in the year compared to higher-latitude areas.

Figure 6 shows the spatial distribution of the maximum TWS deficit for each USDM-classified drought category during 2011-12 and the corresponding monthly TWS standard deviation. We find that it takes a larger TWS deficit to reach the same USDM-classified drought 

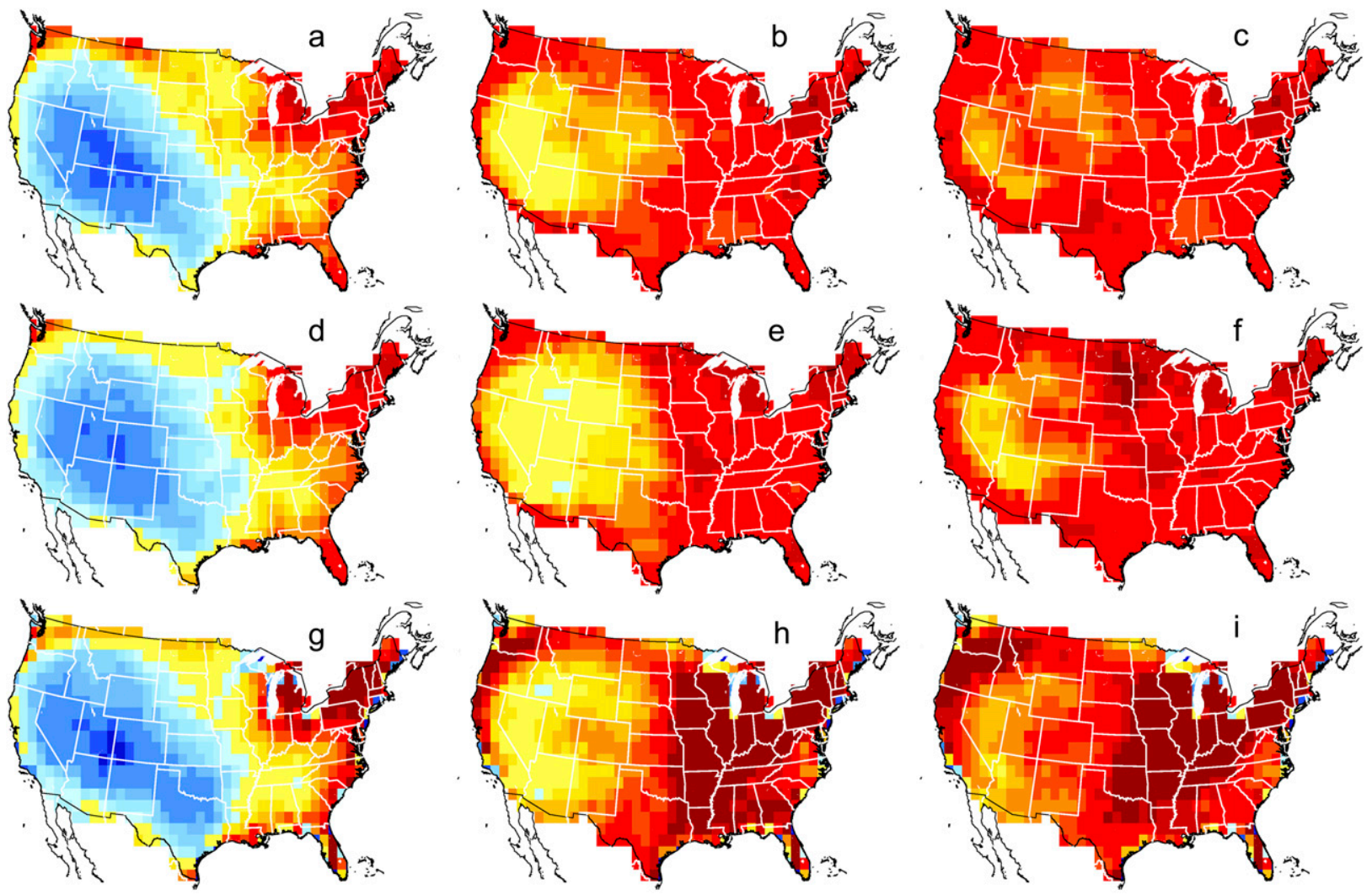

ratio of agreement

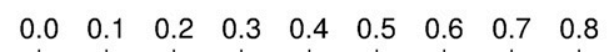

FIG. 4. (a) The ratio of the number of months for which GRACE-DSI and USDM yield the same drought category to the total number of months considered. (b) As in (a), but with the USDM series biased by one category milder (i.e., USDM-1) at every grid cell. (c) As in (b), with the USDM series biased by two categories milder (i.e., USDM-2). Note that the no-drought category minus one or two categories is still considered no-drought. (d)-(f) As in (a)-(c), but replacing GRACE-DSI with PDSI-Z. (g)-(i) As in (a)-(c) but replacing GRACEDSI with the original PDSI.

category in the East, where the climate is humid and the TWS variability is large, than in the West where the climate is drier and the TWS variability is small. This spatial pattern agrees with the east-west decreasing gradient in long-term mean and variability of annual precipitation (Fig. S2), illustrating that it is important to normalize TWS deficit with regional hydroclimatological variability in the GRACE-DSI algorithm for drought severity categorization and drought comparison across space and time.

\section{Discussion}

The GRACE-DSI is based on direct measurements of soil water balance that account for water supply and demand, which enables a globally consistent hydrological drought monitoring. The GRACE-DSI differs from Thomas et al. (2014) and other indices using GRACE alone because it accounts for the regional variability in TWS that directly affects the characterization of drought (Fig. 6). For instance, Thomas et al. (2014) observe a peak TWS deficit of $66 \mathrm{~km}^{3}$ in southeastern United States in November 2007 and a peak TWS deficit of $68 \mathrm{~km}^{3}$ in Texas in January 2013, both of which equal about a 9-cm water-equivalent deficit. The January TWS variability is larger in Texas than November TWS variability in southeastern United States, which means that Texas naturally experiences a wider range of dryness and wetness in January than the southeastern United States in November. Therefore, the GRACE-DSI ranks the same 9-cm water-equivalent deficit one to two categories milder in Texas than in the southeastern United States (Figs. 2b,c). This result agrees with the USDM classification of these two drought events (Fig. S3).

The GRACE-DSI provides consistent and complementary information to the PDSI that strengthens the 

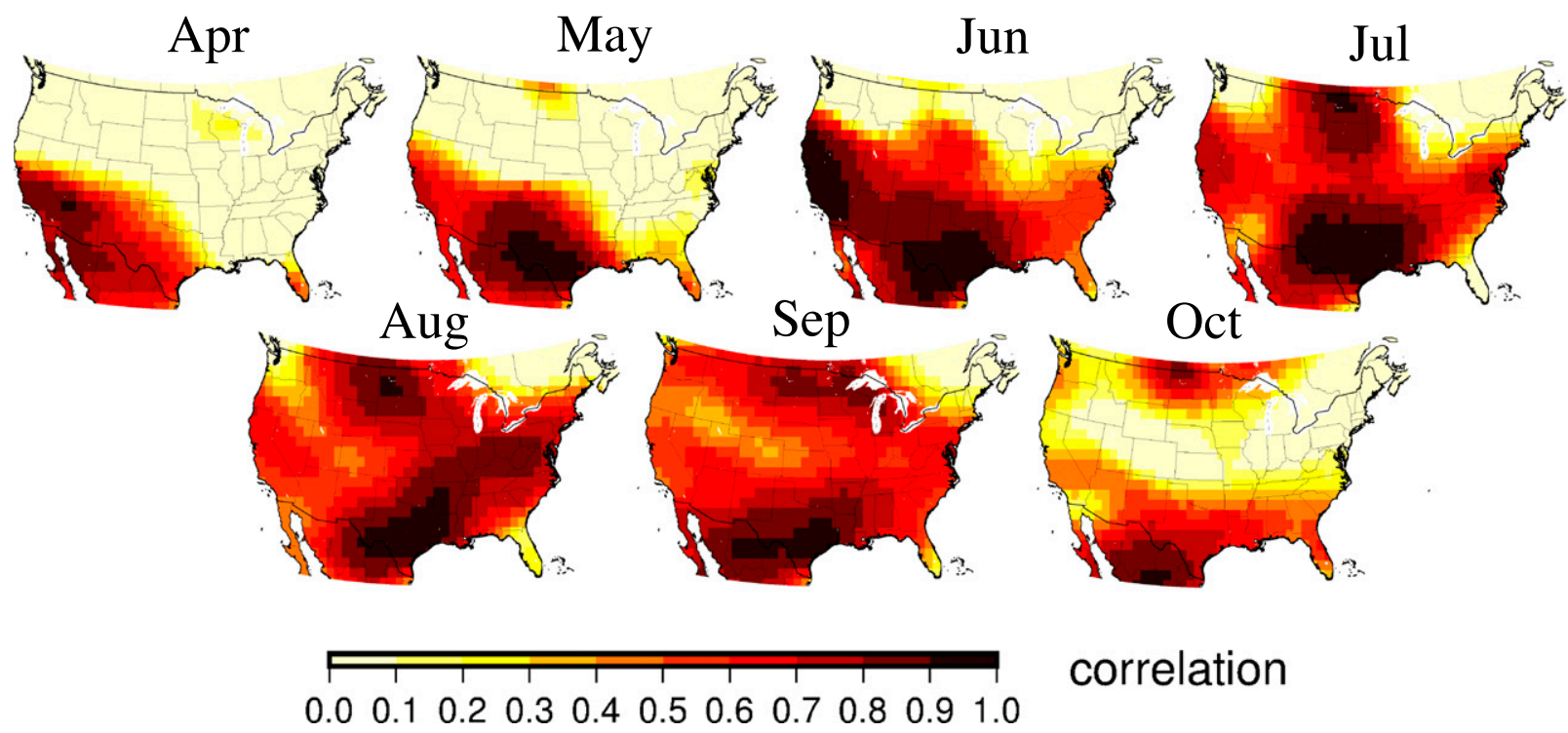

\section{correlation}

FIG. 5. Monthly GRACE-DSI and MODIS NDVI correlation coefficients during the growing season (April-October). Correlation coefficient higher than 0.5 is significant at $90 \%$ confidence level.

analysis of drought conditions. The GRACE-DSI is sensitive to terrestrial water storage changes, whereas the PDSI is responsive to surface SM and atmospheric moisture deficits (Dai 2011). The GRACE-DSI can lag the PDSI by 1 month in detecting drought onset and recovery (e.g., Fig. $2 \mathrm{~g}$ ), which is consistent with the different response time of near-surface conditions and overall water storage (Van Loon 2015). During the 2012 drought in the northwestern Plains, the PDSI decreased earlier than SM probably because of warming-induced atmospheric moisture stress as the PDSI is sensitive to air temperature (Hu and Willson 2000). In contrast, the GRACE-DSI decreases later than SM, indicating more rapid depletion of surface SM than deeper groundwater. An apparent drought recovery is also detected by both GRACE-DSI and PDSI in spring 2013, consistent with previous studies (Hoerling et al. 2014; Wang et al. 2014). During the analyzed period, GRACE-DSI and PDSI also detect different trends in the northwestern Plains associated with changes in overall and shallow-depth water balance, respectively (Figs. 3b-d). We find that for location 1 (Fig. 3b), for instance, their temporal correlation increases from $0.25(p<0.01)$ to $0.44(p<0.001)$ after prewhitening (Text S3 in the online supplemental material, Fig. S4). For the rest of the CONUS, correlation between prewhitened GRACE-DSI and PDSI time series is significant but generally of smaller magnitude compared to those shown in Fig. 3a, indicating that both drought indices capture consistent trends.

The GRACE-DSI and PDSI-Z both underestimate the severity of USDM-classified drought by one to two categories in the western United States (Fig. 4). The mismatch pattern between the original PDSI (normalized using $1950-79$ as the baseline period) and USDM is consistent with the patterns between PDSI-Z and USDM and between GRACE-DSI and USDM. This indicates that the short normalization baseline period (2002-14) in GRACE-DSI and PDSI-Z does not account for their differences with USDM. Instead, the composite nature of USDM and the inclusion of subjective information from local experts might account for its mismatch with GRACE-DSI and PDSI (Anderson et al. 2011; Hao and Singh 2015).

The favorable GRACE-DSI and NDVI correspondence indicates that GRACE-DSI is sensitive to water supply constraints influencing vegetation growth. The correlation is higher in the middle of the growing season than during green-up and senescence when solar radiation and temperature are important factors controlling vegetation growth ( $\mathrm{Ji}$ and Peters 2003; Karnieli et al. 2010; Forkel et al. 2015). The GRACE-DSI also captures the characteristic latitudinal shift of the vegetationmoisture relationship (Karnieli et al. 2010, Yi et al. 2010), whereby the NDVI correlation weakens from lower to higher latitudes due to increasing cold temperature and energy constraints on vegetation growth. Similar correlation patterns are also found between the PDSI-Z and NDVI (Text S4, Fig. S5).

The 2002-14 period may be too short to characterize the full range of dryness and wetness for which a climatology of at least 30 years is desired. We use Levene's test (Levene 1960) to evaluate the difference in PDSI variability of the 13-yr (2002-14) period from a 33-yr (1982-2014) climatology. We find that in $40 \%$ of the 


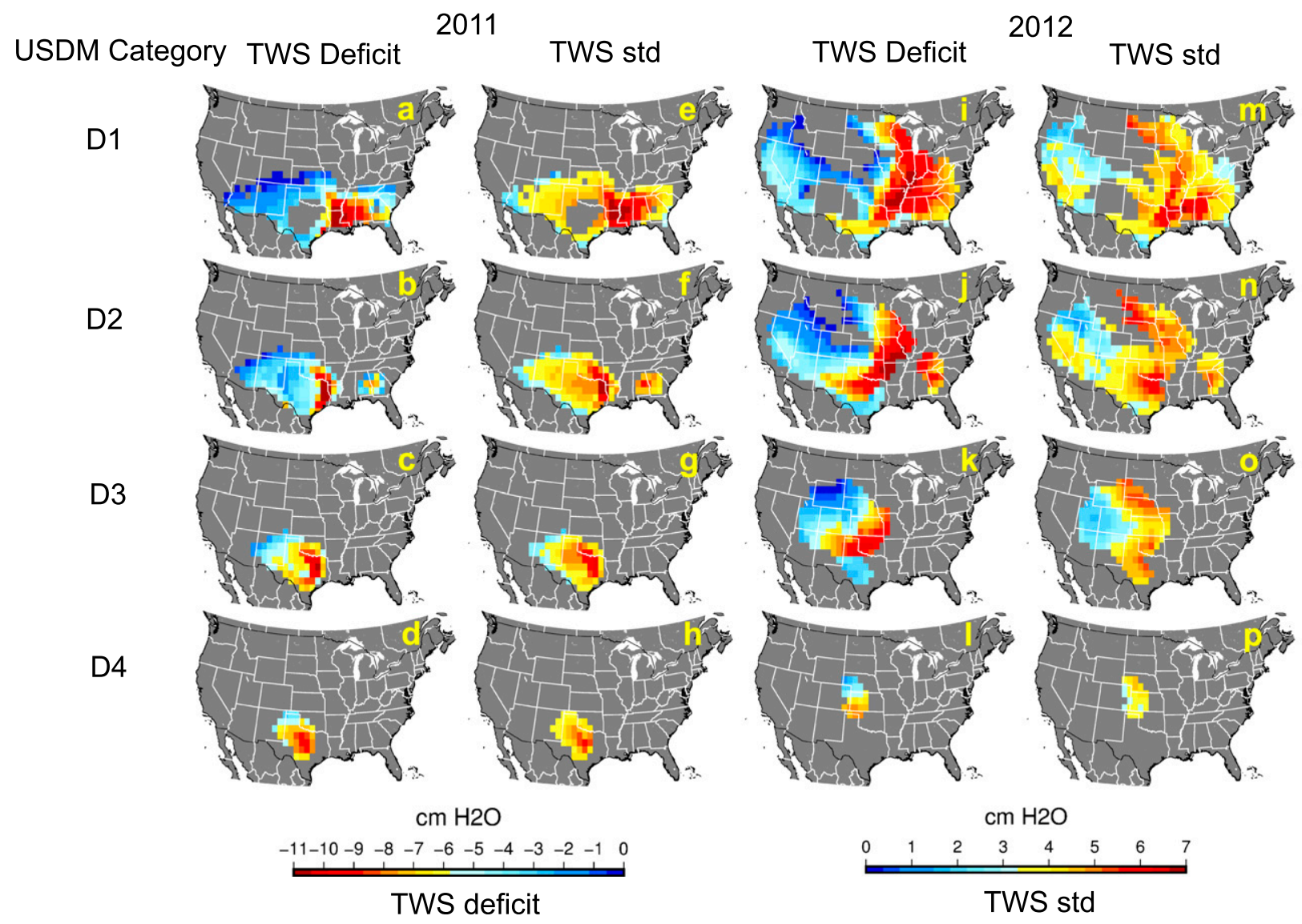

FIG. 6. (a)-(d) The maximum TWS deficit observed in regions where D1-D4 drought, respectively, has been reported by the USDM in 2011. (e)-(h) The TWS standard deviation for the calendar month when the maximum TWS deficit is observed in 2011, as seen in (a)-(d). (i)-(l) As in (a)-(d), but for 2012. (m)-(p) As in (e)-(h), but for 2012.

CONUS, the standard deviations of PDSI are different between the two periods $(p<0.1)$; these regions have experienced a narrower range of wetness and dryness in 2002-14 than in 1982-2014. We calculate the root-meansquare error between PDSI-Zs referenced to those two periods. We find that, using the 13-yr climatology, we underestimate the drought by one category in $40 \%$ of the CONUS due to the fact that the 2002-14 period is drier than 1982-2014 (Fig. 7a). Therefore, we infer that using the 13-yr period to calculate GRACE-DSI does not affect drought category characterization in the majority of the CONUS.

Because of the relatively short data record, using all available GRACE solutions to estimate the monthly TWS climatology mean and standard deviation in GRACE-DSI calculation is currently optimal. This limitation may change the characterization of past drought events when new GRACE solutions become available. To understand how the baseline affects the GRACE-DSI results, we calculate seven alternative GRACE-DSI records using the TWS mean and standard deviation calculated from baseline lengths ranging from 6-yr (2002-07) to 12-yr (2002-13) sequentially. The spatial patterns of these alternative GRACE-DSI records are very similar in the CONUS. Figures $7 \mathrm{~b}$ and $7 \mathrm{c}$ show the area-weighted annual spatial correlation coefficients $(R)$ and Nash-Sutcliffe efficiency coefficients (NS; Nash and Sutcliffe 1970) between these alternative GRACE-DSIs and the 2002-14 baseline GRACE-DSI over the CONUS. When there are at least 9 years of GRACE record, the GRACE-DSI does not change significantly over longer baseline periods. In other words, the characterization of a drought event in 2010 using the 2002-10 baseline would not change significantly when the GRACE-DSI is updated four years later using the 2002-14 baseline. The GRACE-DSI can eventually be normalized to a fixed baseline when the GRACE record will expand to a climatological length.

\section{Conclusions}

We present a novel drought severity index (DSI) derived solely from GRACE satellite observations. The 

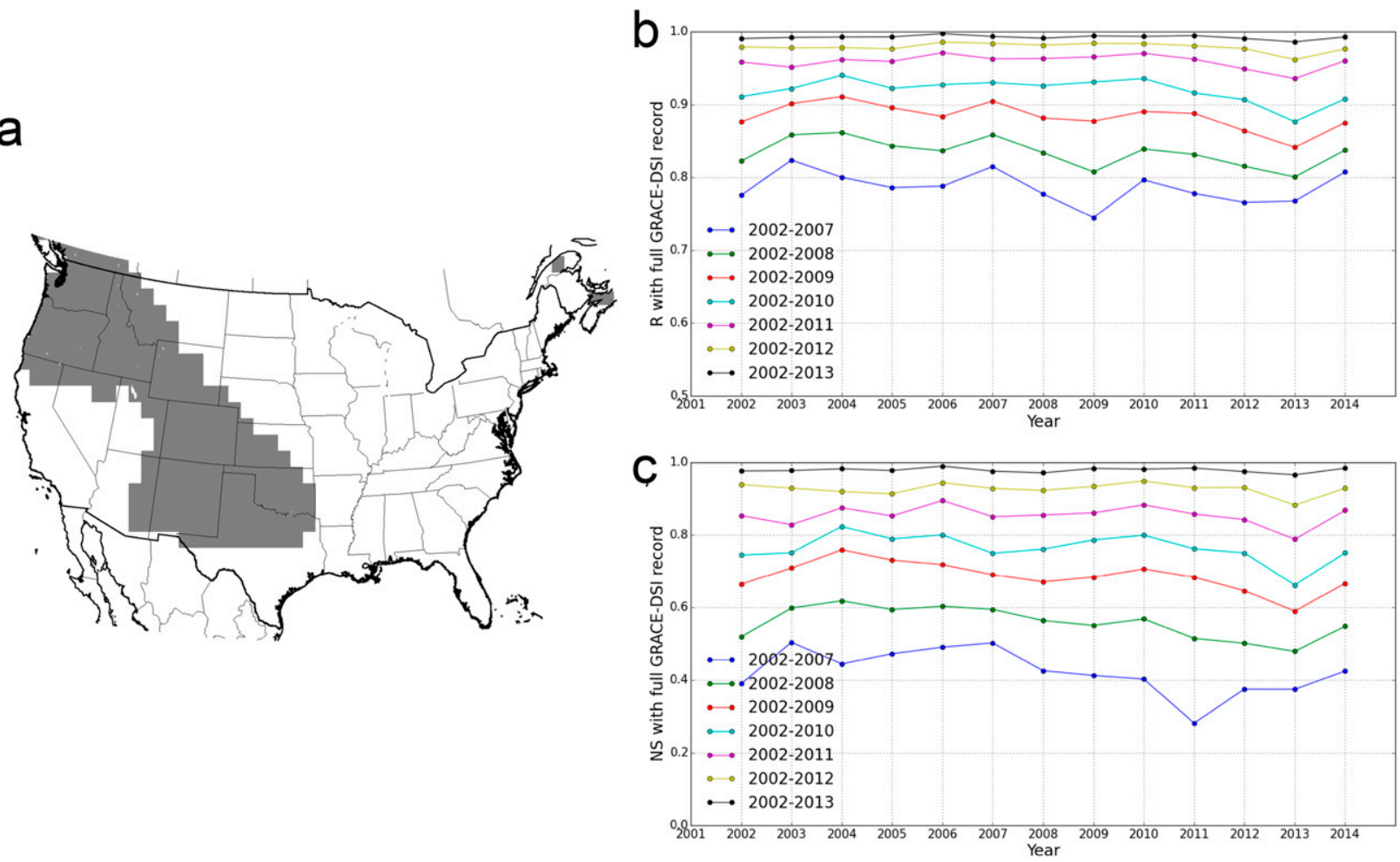

FIG. 7. (a) In the gray regions, PDSI-Z underestimates drought by one category when using the 2002-14 climatology rather than the 1982-2014 climatology. (b) The area-weighted annual spatial correlation coefficients between the 2002-14 baseline GRACEDSI and seven alternative GRACE-DSI calculated from varying baselines. (c) As in (b), but for the Nash-Sutcliffe efficiency coefficients.

large footprint of GRACE-DSI makes it useful for regional- to global-scale hydrological drought assessment. We demonstrate that the GRACE-DSI complements traditional drought metrics such as the PDSI by providing complementary information about deeper water storage changes which affect soil moisture recharge and drought recovery. This is of potential use in drought propagation research, the knowledge of which is imperative to the prediction of hydrological drought (Van Loon 2015). This is also of potential use in developing and improving composite and multi-indicator drought models (AghaKouchak et al. 2015), such as the USDM, with which the GRACE-DSI has good spatial agreement in drought detection. In addition, the GRACEDSI includes moisture variations from the plant root zone and the correspondence between GRACE-DSI and MODIS NDVI over the CONUS manifests spatial and seasonal characteristics of water supply constraints influencing vegetation growth. The GRACE-DSI can therefore be useful to study water-plant relations. The GRACE-DSI also captures human impacts on drought and water resource management, which makes it advantageous to study drought in the Anthropocene (Sivapalan et al. 2012; Van Loon et al. 2016). Combing
GRACE-DSI with traditional drought metrics might enable a partition of drought impact into natural and anthropogenic components. The GRACE-DSI is also of use to the hydrologic modeling community because it provides an independent observation benchmark for evaluating model-based drought monitoring tools. Currently, GRACE rapid solutions are generated using the L1B data product within $24 \mathrm{~h}$ of data acquisition, but with limited data availability. For the GRACE Follow-On mission scheduled for launch between December 2017 and January 2018, this product will become a standard level 3 product, thereby providing near real-time information for operational drought monitoring.

Acknowledgments. This work was performed at the University of California, Irvine, under grants from NASA's Terrestrial Hydrology, IDS, cryosphere, Earth and Space Science Fellowship (NNX16AO64H) programs, and the Gordon and Betty Moore Foundation (Grant GBMF3269). The GRACE-DSI and other data are available upon request to the authors. We thank three anonymous reviewers and editor Dr. Aiguo Dai for their careful reviews. 


\section{REFERENCES}

A, G., J. Wahr, and S. Zhong, 2013: Computations of the viscoelastic response of a 3-D compressible Earth to surface loading: An application to Glacial Isostatic Adjustment in Antarctica and Canada. Geophys. J. Int., 192, 557-572, doi:10.1093/gii/ggs030.

_- I. Velicogna, J. S. Kimball, and Y. Kim, 2015: Impact of changes in GRACE derived terrestrial water storage on vegetation growth in Eurasia. Environ. Res. Lett., 10, 124024, doi:10.1088/1748-9326/10/12/124024.

AghaKouchak, A., A. Farahmand, F. S. Melton, J. Teixeira, M. C. Anderson, B. D. Wardlow, and C. R. Hain, 2015: Remote sensing of drought: Progress, challenges and opportunities. Rev. Geophys., 53, 452-480, doi:10.1002/2014RG000456.

Anderson, M. C., C. Hain, B. Wardlow, A. Pimstein, J. R. Mecikalski, and W. P. Kustas, 2011: Evaluation of drought indices based on thermal remote sensing of evapotranspiration over the continental United States. J. Climate, 24, 20252044, doi:10.1175/2010JCLI3812.1.

—, , J. Otkin, X. Zhan, K. Mo, M. Svoboda, B. Wardlow, and A. Pimstein, 2013: An intercomparison of drought indicators based on thermal remote sensing and NLDAS-2 simulations with U.S. Drought Monitor classifications. J. Hydrometeor., 14, 1035-1056, doi:10.1175/JHM-D-12-0140.1.

Cao, Y., Z. Nan, and G. Cheng, 2015: GRACE gravity satellite observations of terrestrial water storage changes for drought characterization in the arid land of northwestern China. Remote Sens., 7, 1021-1047, doi:10.3390/rs70101021.

Castle, S. L., B. F. Thomas, J. T. Reager, M. Rodell, S. C. Swenson, and J. S. Famiglietti, 2014: Groundwater depletion during drought threatens future water security of the Colorado River Basin. Geophys. Res. Lett., 41, 5904-5911, doi:10.1002/2014GL061055.

Chen, J. L., C. R. Wilson, B. D. Tapley, Z. L. Yang, and G. Y. Niu, 2009: 2005 drought event in the Amazon River basin as measured by GRACE and estimated by climate models. J. Geophys. Res., 114, B05404, doi:10.1029/2008JB006056.

Cheng, M., B. D. Tapley, and J. C. Ries, 2013: Deceleration in the Earth's oblateness. J. Geophys. Res. Solid Earth, 118, 740-747, doi:10.1002/jgrb.50058.

Dai, A., 2011: Characteristics and trends in various forms of the Palmer Drought Severity Index during 1900-2008. J. Geophys. Res., 116, D12115, doi:10.1029/2010JD015541.

_ 2013: Increasing drought under global warming in observations and models. Nat. Climate Change, 3, 52-58, doi:10.1038/ nclimate1633.

_ , K. E. Trenberth, and T. Qian, 2004: A global dataset of Palmer Drought Severity Index for 1870-2002: Relationship with soil moisture and effects of surface warming. J. Hydrometeor., 5, 1117-1130, doi:10.1175/JHM-386.1.

Famiglietti, J. S., 2014: The global groundwater crisis. Nat. Climate Change, 4, 945-948, doi:10.1038/nclimate2425.

Forkel, M., and Coauthors, 2015: Codominant water control on global interannual variability and trends in land surface phenology and greenness. Global Change Biol., 21, 3414-3435, doi:10.1111/ gcb.12950.

Friedl, M. A., and Coauthors, 2010: MODIS Collection 5 global land cover: Algorithm refinements and characterization of new datasets. Remote Sens. Environ., 114, 168-182, doi:10.1016/ j.rse.2009.08.016.

Hao, Z., and V. P. Singh, 2015: Drought characterization from a multivariate perspective: A review. J. Hydrol., 527, 668-678, doi:10.1016/j.jhydrol.2015.05.031.
Hoerling, M., J. Eischeid, A. Kumar, R. Leung, A. Mariotti, K. Mo, S. Schubert, and R. Seager, 2014: Causes and predictability of the 2012 Great Plains drought. Bull. Amer. Meteor. Soc., 95, 269-282, doi:10.1175/BAMS-D-13-00055.1.

Houborg, R., M. Rodell, B. Li, R. Reichle, and B. F. Zaitchik, 2012: Drought indicators based on model-assimilated Gravity Recovery and Climate Experiment (GRACE) terrestrial water storage observations. Water Resour. Res., 48, W07525, doi:10.1029/2011WR011291.

Hu, Q., and G. D. Willson, 2000: Effects of temperature anomalies on the Palmer Drought Severity Index in the central United States. Int. J. Climatol., 20, 1899-1911, doi:10.1002/ 1097-0088(200012)20:15<1899::AID-JOC588>3.0.CO;2-M.

Huete, A., K. Didan, T. Miura, E. P. Rodriguez, X. Gao, and L. G. Ferreira, 2002: Overview of the radiometric and biophysical performance of the MODIS vegetation indices. Remote Sens. Environ., 83, 195-213, doi:10.1016/S0034-4257(02)00096-2.

Ji, L., and A. J. Peters, 2003: Assessing vegetation response to drought in the northern Great Plains using vegetation and drought indices. Remote Sens. Environ., 87, 85-98, doi:10.1016/ S0034-4257(03)00174-3.

Karnieli, A., and Coauthors, 2010: Use of NDVI and land surface temperature for drought assessment: Merits and limitations. J. Climate, 23, 618-633, doi:10.1175/2009JCLI2900.1.

Landerer, F. W., and S. C. Swenson, 2012: Accuracy of scaled GRACE terrestrial water storage estimates. Water Resour. Res., 48, W04531, doi:10.1029/2011WR011453.

Leblanc, M. J., P. Tregoning, G. Ramillien, S. O. Tweed, and A. Fakes, 2009: Basin-scale, integrated observations of the early 21st century multiyear drought in southeast Australia. Water Resour. Res., 45, W04408, doi:10.1029/2008WR007333.

Levene, H., 1960: Robust tests for equality of variances. Contributions to Probability and Statistics: Essays in Honor of Harold Hotelling, I. Olkin et al., Eds., Stanford University Press, 278-292.

Liu, Y. Y., R. M. Parinussa, W. A. Dorigo, R. A. M. de Jeu, W. Wagner, A. I. J. M. van Dijk, M. F. McCabe, and J. P. Evans, 2011: Developing an improved soil moisture dataset by blending passive and active microwave satellite-based retrievals. Hydrol. Earth Syst. Sci., 15, 425-436, doi:10.5194/hess-15-425-2011.

—, W. A. Dorigo, R. M. Parinussa, R. A. M. de Jeu, W. Wagner, M. F. McCabe, J. P. Evans, and A. I. J. M. van Dijk, 2012: Trend-preserving blending of passive and active microwave soil moisture retrievals. Remote Sens. Environ., 123, 280-297, doi:10.1016/j.rse.2012.03.014.

Long, D., B. R. Scanlon, L. Longuevergne, A. Y. Sun, D. N. Fernando, and H. Save, 2013: GRACE satellite monitoring of large depletion in water storage in response to the 2011 drought in Texas. Geophys. Res. Lett., 40, 3395-3401, doi:10.1002/grl.50655.

McCandless, S. E., 2014: Utilizing GRACE TWS, NDVI, and precipitation for drought identification and classification in Texas. M.S. thesis, Dept. of Aerospace Engineering, The University of Texas at Austin, $121 \mathrm{pp}$.

Mishra, A. K., and V. P. Singh, 2010: A review of drought concepts. J. Hydrol., 391, 202-216, doi:10.1016/j.jhydrol.2010.07.012.

Mu, Q., M. Zhao, J. S. Kimball, N. G. McDowell, and S. W. Running, 2013: A remotely sensed global terrestrial drought severity index. Bull. Amer. Meteor. Soc., 94, 83-98, doi:10.1175/BAMS-D-11-00213.1.

Nash, J. E., and J. V. Sutcliffe, 1970: River flow forecasting through conceptual models part I-A discussion of principles. J. Hydrol., 10, 282-290, doi:10.1016/0022-1694(70)90255-6.

NOAA, 2012: State of the Climate: Drought for Annual 2011. National Centers for Environmental Information. [Available online at http://www.ncdc.noaa.gov/sotc/drought.] 
— 2015: State of the Climate: Drought for Annual 2014. National Centers for Environmental Information. [Available online at http://www.ncdc.noaa.gov/sotc/drought.]

Palmer, W. C., 1965: Meteorological drought. U.S. Weather Bureau Rep., 65 pp.

Reager, J. T., A. C. Thomas, E. A. Sproles, M. Rodell, H. K. Beaudoing, B. Li, and J. S. Famiglietti, 2015: Assimilation of GRACE terrestrial water storage observations into a land surface model for the assessment of regional flood potential. Remote Sens., 7, $14663-14$ 679, doi:10.3390/rs71114663.

Savtchenko, A. K., G. Huffman, and B. Vollmer, 2015: Assessment of precipitation anomalies in California using TRMM and MERRA data. J. Geophys. Res. Atmos., 120, 8206-8215, doi:10.1002/2015JD023573.

Schwalm, C. R., and Coauthors, 2012: Reduction in carbon uptake during turn of the century drought in western North America. Nat. Geosci., 5, 551-556, doi:10.1038/ngeo1529.

Sivapalan, M., H. H. G. Savenije, and G. Blöschl, 2012: Sociohydrology: A new science of people and water. Hydrol. Processes, 26, 1270-1276, doi:10.1002/hyp.8426.

Svoboda, M., and Coauthors, 2002: The Drought Monitor. Bull. Amer. Meteor. Soc., 83, 1181-1190, doi:10.1175/ 1520-0477(2002)083<1181:TDM >2.3.CO;2.

Swenson, S., and J. Wahr, 2006: Post-processing removal of correlated errors in GRACE data. Geophys. Res. Lett., 33, L08402, doi:10.1029/2005GL025285.

_ - D. Chambers, and J. Wahr, 2008: Estimating geocenter variations from a combination of GRACE and ocean model output. J. Geophys. Res., 113, B08410, doi:10.1029/2007JB005338.

Thomas, A. C., J. T. Reager, J. S. Famiglietti, and M. Rodell, 2014: A GRACE-based water storage deficit approach for hydrological drought characterization. Geophys. Res. Lett., 41, 1537-1545, doi:10.1002/2014GL059323.
Trenberth, K. E., A. Dai, G. van der Schrier, P. D. Jones, J. Barichivich, K. R. Briffa, and J. Sheffield, 2014: Global warming and changes in drought. Nat. Climate Change, $\mathbf{4}$, 17-22, doi:10.1038/nclimate2067.

van der Schrier, G., J. Barichivich, K. R. Briffa, and P. D. Jones, 2013: A scPDSI-based global data set of dry and wet spells for 1901-2009. J. Geophys. Res. Atmos., 118, 4025-4048, doi:10.1002/jgrd.50355.

Van Loon, A. F., 2015: Hydrological drought explained. Wiley Interdiscip. Rev.: Water, 2, 359-392, doi:10.1002/wat2.1085.

- , and Coauthors, 2016: Drought in the Anthropocene. Nat. Geosci., 9, 89-91, doi:10.1038/ngeo2646.

Velicogna, I., and J. Wahr, 2006: Measurements of time-variable gravity show mass loss in Antarctica. Science, 311, 1754-1756, doi:10.1126/science.1123785.

Vicente-Serrano, S. M., and Coauthors, 2013: Response of vegetation to drought time-scales across global land biomes. Proc. Natl. Acad. Sci. USA, 110, 52-57, doi:10.1073/pnas.1207068110.

Wahr, J., M. Molenaar, and F. Bryan, 1998: Time variability of the Earth's gravity field: Hydrological and oceanic effects and their possible detection using GRACE. J. Geophys. Res., 103, 30 205-30229, doi:10.1029/98JB02844.

Wang, H., S. Schubert, R. Koster, Y.-G. Ham, and M. Suarez, 2014: On the role of SST forcing in the 2011 and 2012 extreme U.S. heat and drought: A study in contrasts. J. Hydrometeor., 15, 1255-1273, doi:10.1175/JHM-D-13-069.1.

Yi, C., and Coauthors, 2010: Climate control of terrestrial carbon exchange across biomes and continents. Environ. Res. Lett., 5, 034007, doi:10.1088/1748-9326/5/3/034007.

Yirdaw, S., K. Snelgrove, and C. Agboma, 2008: GRACE satellite observations of terrestrial moisture changes for drought characterization in the Canadian prairie. J. Hydrol., 356, 8492, doi:10.1016/j.jhydrol.2008.04.004. 